\title{
Markets for Product Modification Information
}

\author{
Ganesh Iyer • David Soberman \\ John M. Olin School of Business, Washington University, St. Louis, Missouri, iyer@mail.olin.wustl.edu \\ INSEAD, France, david.soberman@insead.fr
}

\begin{abstract}
An important product strategy for firms in mature markets is value-adding modifications to existing products. Marketing information that reveals consumers' preferences, buying habits, and lifestyle is critical for the identification of such product modifications. We consider two types of valueadding modifications that are often facilitated by marketing information: retention-type modifications that increase the attractiveness of a product to a firm's loyal customers, and conquesting-type modifications that allow a firm to increase the appeal of its product to a competitor's loyal customers. We examine two aspects of the markets for product modification information: (1) the manner in which retention and conquesting modifications affect competition between downstream firms, and (2) the optimal selling and pricing policies for a vendor who markets product modification information. We consider several aspects of the vendor's contracting problem, including how a vendor should package and target the information to the downstream firms and whether the vendor should limit the type of information that is sold. This research also examines when a vendor can gain by offering exclusivity to a firm.
\end{abstract}

We address these issues in a model consisting of an information vendor facing two downstream firms that sell differentiated products. The model analyzes how information contracting is affected by differentiation in the downstream market and the quality of the information (in terms of how "impactful" the resulting modifications are). We analyze two possible scenarios. In the first, the information facilitates modifications that increase the appeal of products to the loyal customers of only one of the two downstream firms (i.e., one-sided information). In the second scenario, the information facilitates modifications that are attractive to the loyal consumers of both the firms (i.e., two-sided information).

The effect of modifications on downstream competition depends on whether they are of the retention or the conquesting type. A retention-type modification increases the "effective" differentiation between the firms and softens price competition. Conquesting modifications, however, have benefits as well as associated costs. A conquesting modification of low impact reduces the "effective" differentiation between competing products and leads to increased price competition. However, when conquesting modifications are of sufficiently high impact, they also have the benefit of helping a firm to capture the customers of the competitor.

The vendor's strategy for one-sided information always involves selling to one firm, the firm for which the modifications are of the retention type. When the identified modifications are of low impact, this result is expected because conquesting modifications are profit-reducing for downstream firms. However, even when the information identifies highimpact modifications (and positive profits are generated by selling the information as conquesting information), the vendor is strictly better off by targeting his information to the firm for which the modification is the retention type. With two-sided information, the equilibrium strategy is for the vendor to sell the complete packet of information (information on both retention and conquesting modifications) to both downstream firms. However, in equilibrium, both firms only implement retention-type modifications. The information on conquesting modifications is "passive" in the sense that it is never used by downstream firms. Yet the vendor makes strictly greater profit by including it in the packet. This obtains because the price charged for information depends critically on the situation an individual firm encounters by not buying the information. The presence of conquesting information in the packet puts a nonbuyer in a worse situation, and this underlines the "passive power of information." The vendor gains by including the conquesting information even though it is not used in equilibrium.

(Marketing of Information; Information Packaging; Selling Contracts; Retention Modifications; Conquesting Modifications; Product Modifications; Passive Power of Information) 


\section{Introduction}

\subsection{Background}

Marketing information sold by syndicated data vendors is one the fastest growing segments of market research in the 1990s. ${ }^{1}$ Syndicated vendors are particularly active in providing marketing managers with information that helps to formulate and modify product strategy. Vendors such as ICOM, Acxiom, Yankelovich, and NFO Worldwide, to mention a few, offer syndicated systems that track ongoing changes in consumer preferences, brand attitudes, buying habits, lifestyle, and demographic trends. This information provides marketers with knowledge on how to add value to their product offerings. In many mature packagedgoods markets, this information is a critical resource that aids in the development of competitive strategies. Table 1 provides details of syndicated information systems offered by 6 of the top 50 market research organizations in the United States that help clients in designing or modifying their products.

This type of information is particularly important because almost $90 \%$ of new product activity involves modifications to existing products rather than completely new products. These modifications include changes to product features, line extensions, positioning, and packaging. ${ }^{2}$ Syndicated database systems of the type shown in Table 1 have some critical advantages in this context. First, they help clients to continuously monitor changes in consumer and market trends (with associated implications for their products). Second, the increasing technological sophistication of syndicated databases enables firms to add value in a highly targeted fashion. The following example illustrates how information is used to modify and add value to a product.

ExAmple. ICOM is one of North America's fastest growing syndicated providers of database marketing information. The company has developed a relational

\footnotetext{
${ }^{1}$ The top 50 U.S. market research firms grew at $9 \%$ and reported worldwide revenues of $\$ 5.96$ billion in 1998 (see "Business Report on the Marketing Research Industry," Marketing News, June 7, 1999).

${ }^{2}$ Gorman's New Product News reported that $89 \%$ of the 6,125 new products accepted by grocery stores in the first five months of 1991 were line extensions.
}

database that incorporates household-level information on demographics, activities, preferences, and brand consumption in a number of product categories. Some of the most aggressive users of ICOM's data are pharmaceutical companies that compete in OTC categories such as pain relievers. Motrin (Johnson \& Johnson) and Advil (American Home Products or AHP) are ibuprofen-based products that compete in the OTC pain relief market. Both brands have the same active ingredient (ibuprofen). However, analysis of ICOM's database revealed that Advil's usage was relatively high among headache sufferers. In contrast, Motrin usage was higher among sufferers of backache and menstrual cramps. In March of 1999 using ICOM's database, J\&J developed a booklet and a marketing program specifically targeted at the consumers in the database who were identified as frequent sufferers of backaches and menstrual cramps. The booklet was designed to "educate" consumers about the efficacy of Motrin for this type of pain relief. Clearly, J\&J is using this particular initiative to build Motrin's appeal with its more loyal users.

Marketing information available from the ICOM database enabled J\&J to add value to Motrin by providing valuable information/knowledge that was relevant to its loyal users. This is labeled as a retention-type modification. However, J\&J could also have used the information to increase the appeal of Motrin among consumers who are loyal to Advil by highlighting its efficacy for headaches. We call this a conquesting-type modification. ${ }^{3}$

The purpose of this article is to examine the optimal strategies for a syndicated data vendor who markets information useful for guiding the product strategy of firms in fast-moving consumer goods markets. This requires us to analyze how information, which points to retention or conquesting modifications, affects competition between downstream firms. Several important questions arise in the context of understanding the information vendor's options and their subsequent impact on market competition:

\footnotetext{
${ }^{3}$ The paper focuses on the role of value-adding modifications in mature markets such as packaged goods, beer, OTC medicines, where firms primarily compete for market share. Consequently, the role of product modifications is to retain one's loyal customers or to attract the existing customers of a competitor.
} 


\begin{tabular}{|c|c|c|}
\hline Company/Subsidiary & $\begin{array}{l}1998 \text { Revenue } \\
\text { (Mn.) }\end{array}$ & Description of Syndicated Information Products \\
\hline $\begin{array}{l}\text { The NPD Group Inc., Port } \\
\text { Washington, N.Y. }\end{array}$ & 138.50 & $\begin{array}{l}\text { Operates a consumer panel consisting of } 400,000 \text { households and a monthly omnibus service Insta- } \\
\text { vue. These services use the NPD Powerview Concept Management system to track usage and } \\
\text { attitudes and help clients optimize product management and concept development on an ongoing } \\
\text { basis. }\end{array}$ \\
\hline $\begin{array}{l}\text { Market Facts Inc., Arlington } \\
\text { Heights III. }\end{array}$ & 136.50 & $\begin{array}{l}\text { Has a Consumer Mail Panel of } 525,000 \text { households in U.S. and Canada. This database is used in } \\
\text { services such as ProductQuest and BrandVision that aid clients in product strategy and brand } \\
\text { management. }\end{array}$ \\
\hline $\begin{array}{l}\text { Opinion Research Corp. } \\
\text { International, Princeton, N.J. }\end{array}$ & 73.20 & $\begin{array}{l}\text { Offers several syndicated research services including Brand Perceptions and Customers-for-Life. } \\
\text { These services help clients to analyze brand loyalty antecedents and customer retention variables. }\end{array}$ \\
\hline $\begin{array}{l}\text { Roper Starch Worldwide Inc., } \\
\text { Harrison, N.Y. }\end{array}$ & 51.30 & $\begin{array}{l}\text { Roper Reports is a research-tracking service on Americans' attitudes, opinions, values, and lifestyles. } \\
\text { It provides clients insights into the perception and impact of product attributes, features, and } \\
\text { benefits. Client support includes ongoing recommendations in the areas of product positioning and } \\
\text { product development. }\end{array}$ \\
\hline Elrick \& Lavidge, Tucker, Ga. & 32.70 & $\begin{array}{l}\text { E\&L's Database Research Center is syndicated and multiclient service. Using this, E\&L conducts } \\
\text { customer analysis including customer acquisition (needs assessment, awareness and usage, and } \\
\text { lost prospect analysis), customer retention (lost customer analysis, vulnerability segmentation), } \\
\text { customer value analysis (competitive positioning and relative value scoring). }\end{array}$ \\
\hline $\begin{array}{l}\text { Yankelovich Partners Inc., } \\
\text { Norwalk, Conn. }\end{array}$ & 27.20 & $\begin{array}{l}\text { - In 1998, YPI acquired AIM, a provider of customized database marketing systems that allow clients } \\
\text { to optimize their acquisition, cross-selling, and retention-marketing operations. }\end{array}$ \\
\hline & & $\begin{array}{l}\text { - Marketers use the Yankelovich Monitor syndicated database to identify the effect of consumer } \\
\text { trends in the marketplace on various marketing-mix activities including product development, brand } \\
\text { management, product positioning, and targeting. }\end{array}$ \\
\hline
\end{tabular}

*Based on information from "Business Report on the Market Research Industry," Marketing News, June 7, 1999.

- Should the vendor sell this information exclusively or broadly within a category?

- Should the vendor's strategy differ depending on whether the information helps a firm to target its own as opposed to its competitor's customers?

- Should the vendor sell complete information packets, or should she limit the type of information that a buyer will receive (e.g., information on own versus competing customers)?

\subsection{Product Modification Information: Taxonomy and Characteristics}

Information vendors such as ICOM provide product modification information to client firms in a broad range of markets. Although the essential function of this information is to facilitate value additions to the product, the manner in which the information works differs widely from one case to the other. Table 2 pro- vides a taxonomy of different types of product modification information.

The first type is information that facilitates modifications to the physical features or attributes of the product. The reformulation of BreathSavers with a chlorophyll dot was a modification to a physical feature of the product. Such a modification makes the product more attractive to consumers who are currently loyal to Clorets (i.e., a conquesting modification). However, marketing information can also facilitate product modifications in the context of the overall product offering. Thus syndicated information can add value through identifying a suitable packaging strategy. For example, the Yankelovich Monitor can identify the consumers in its database who represent the "sporty trendsetter" lifestyle segment. This segment has an interest in socializing and consuming beer in licensed establishments but likes to consumer beer in 
IYER AND SOBERMAN

Markets for Product Modification Information

Table 2 A Taxonomy of Product Modifications That Are Differentially Attractive to Consumers Based on Brand Loyalty

\begin{tabular}{|c|c|c|c|c|c|}
\hline Category/Year & $\begin{array}{l}\text { Focal Brand/ } \\
\text { Company }\end{array}$ & $\begin{array}{c}\text { Key } \\
\text { Competitor }\end{array}$ & Information & $\begin{array}{c}\text { Modification } \\
\text { (Contemplated) }\end{array}$ & $\begin{array}{l}\text { Nature of } \\
\text { Modification }\end{array}$ \\
\hline
\end{tabular}

Product modifications through product features/benefits

\begin{tabular}{|c|c|c|c|c|c|}
\hline Breathmints 1985 & BreathSavers & Clorets & $\begin{array}{l}\text { Clorets loyalty is highly correlated } \\
\text { with belief in the breath-freshening } \\
\text { capability of chlorophyll. }\end{array}$ & $\begin{array}{l}\text { Breathsavers is reformulated with a } \\
\text { green dot of chlorophyll. }\end{array}$ & Conquesting \\
\hline $\begin{array}{l}\text { Specialty } \\
\text { Publications } 1999\end{array}$ & $\begin{array}{l}\text { Gardening } \\
\text { Magazine }\end{array}$ & $\begin{array}{l}\text { Competitive } \\
\text { Gardening } \\
\text { Magazine }\end{array}$ & $\begin{array}{l}\text { Focal magazine loyalty is highly } \\
\text { correlated with interest in drinking } \\
\text { wine. }\end{array}$ & $\begin{array}{l}\text { Magazine adds special section } \\
\text { devoted to wine of month. }\end{array}$ & Retention \\
\hline \multicolumn{6}{|c|}{ Product modifications through packaging } \\
\hline $\begin{array}{l}\text { Family } \\
\text { Restaurants } 1997\end{array}$ & Red Lobster & Long John Silver & $\begin{array}{l}\text { Loyalty to Red Lobster is highly } \\
\text { correlated an interest in experiences } \\
\text { that help to escape the grind of } \\
\text { everyday routine. }\end{array}$ & $\begin{array}{l}\text { Red Lobster converts the exteriors } \\
\text { and interiors of its restaurants to a } \\
\text { "wharfside" look. }\end{array}$ & Retention \\
\hline Light Beer 1991 & Coors Light & Miller Lite & $\begin{array}{l}\text { Loyalty to Coors Light is highly } \\
\text { correlated with the interest in being } \\
\text { able to purchase beer in amounts } \\
\text { less than } 12 \mathrm{oz} \text {. }\end{array}$ & $\begin{array}{l}\text { Coors Light increases availability of } \\
\text { 7-oz. "pony" bottles. }\end{array}$ & Retention \\
\hline
\end{tabular}

Product modifications through services/information augmentation

\begin{tabular}{|c|c|c|c|c|c|}
\hline Cat Food 1999 & Friskies & 9 Lives & $\begin{array}{l}\text { Loyalty to Friskies is highly } \\
\text { correlated with concern for the cat's } \\
\text { welfare and interest in cat-related } \\
\text { activities. }\end{array}$ & $\begin{array}{l}\text { Friskies launches a Cat Club, which } \\
\text { provides information on cat care, cat } \\
\text { shows, and attractive special offers. }\end{array}$ & Retention \\
\hline $\begin{array}{l}\text { Ibuprofen Pain } \\
\text { Relievers } 1999\end{array}$ & Motrin & Advil & $\begin{array}{l}\text { Advil users are more likely to take } \\
\text { pain relievers for headaches. Motrin } \\
\text { users were more likely to pain } \\
\text { relievers for relief from backache or } \\
\text { menstrual cramps. }\end{array}$ & $\begin{array}{l}\text { Motrin develops information and a } \\
\text { promotion specifically targeted to } \\
\text { consumers suffering from } \\
\text { backaches. }\end{array}$ & Retention \\
\hline $\begin{array}{l}\text { Shopping Malls } \\
1998\end{array}$ & $\begin{array}{l}\text { Large Suburban } \\
\text { Mall }\end{array}$ & $\begin{array}{l}\text { Key Competitive } \\
\text { Mall }\end{array}$ & $\begin{array}{l}\text { Loyalty to the competitive mall is } \\
\text { highly correlated with specific city } \\
\text { subdivisions. }\end{array}$ & $\begin{array}{l}\text { Focal Mall designs a free-delivery } \\
\text { program focused on subdivisions } \\
\text { loyal to the competitive mall. }\end{array}$ & Conquesting \\
\hline
\end{tabular}

*Modifications shown were considered by the focal company but not always implemented.

smaller amounts than the standard 12-oz. bottle. Based on this information, Coors Light (the preferred brand in this segment) could increase distribution of the 7oz. "pony" bottle to make the brand more attractive to its loyal users. The third type of product modification information follows from Levitt's (1969) concept of the augmented product. The examples in Table 2 show how syndicated data can help manufacturers to "augment" valuable services or information to the core product. The R. L. Polk information adds value by allowing the mall owner to augment the core product (in this case, the mall) through a value-adding freedelivery service program. Similarly, J\&J was able to use the ICOM database to augment the product by providing valuable information to consumers about the efficacy of Motrin for backaches.

In summary, syndicated information might not only have value for consumers in and of itself (as in the pain 
reliever example), but also because it might help develop a packaging change or indicated changes to the existing features of the product. In other words, information in this framework can be thought of as a resource or as knowledge that allows a firm to add value through any component of the product. ${ }^{4}$

\subsection{Framework and Results}

We develop a model of an information vendor selling to two differentiated downstream firms. The model highlights the role of two factors: the degree of differentiation between the downstream firms, and the impact of the information in terms of how valuable the resulting modifications are.

Consider the different situations that an information vendor can face. A vendor might have information that facilitates modifications that are attractive to the loyal consumers of both firms. We define this as two-sided information. An example is the ICOM information that points to marketing activity that yields differential benefits to the users of both Motrin and Advil. An initiative to provide benefits to backache/menstrual cramp sufferers will be more valuable to Motrin users, whereas an initiative to provide benefits to headache sufferers will be more valuable to Advil users. The vendor must decide whether to sell the information to both firms or offer it exclusively to both firms. If the vendor decides to sell to both firms, she must also choose a packaging strategy. The vendor can sell complete information packets (that provide both firms with information that allows modifications for own as well as competitive customers) or limited information packets (for example, selling information that points to retention modifications only).

A second situation is one in which the vendor has information that identifies product changes that are attractive to consumers who are loyal to only one of the firms (we define this as one-sided information). In the

\footnotetext{
${ }^{4}$ Resources other than marketing information can facilitate product modifications. For example, "product design" firms such as the Development Agency and Dollery Rudman assist clients in the redesign of their products. Nevertheless, this article is motivated by the syndicated information industry because marketing information is the most pervasive resource that is used to implement product changes. Even when a company hires a product design expert to effect a product change, information on consumer preferences is an essential prerequisite.
}

Coors Light example, the sporty trendsetter segment is loyal to Coors Light. Thus the knowledge that they would like to consume beer in smaller amounts can be used to effect a pack-size modification that adds value differentially to consumers who are on the Coors Light side of the market. The decision that the vendor faces is whether to sell it to the firm (Coors Light) that currently serves these customers (in which case, the modifications would be retention type), or to the firm that would like to acquire these customers (in which case, the modifications are conquesting type), or to both.

Given the vendor decisions, the downstream firms decide whether or not to buy the information, and once they have purchased information, they decide which (if any) modifications to implement. They then compete by choosing market prices simultaneously.

We find that retention-type modifications unambiguously soften price competition between firms. These modifications make firms behave as if the level of differentiation between them has increased, enabling them to raise prices without the fear of losing existing customers. In fact, even if only one firm implements a retention modification, its strategic effect is to raise equilibrium prices in the market. Conquesting modifications, however, have costs as well as associated benefits. Although a conquesting initiative has a "business stealing" advantage of helping a firm attract the loyal customers of the competitor, it also has the disadvantage of evoking an aggressive pricing response from the competitor. This strategic response of the competitor makes the overall market behave as if effective firm differentiation is reduced, and this exacerbates price competition. When a conquesting modification has low impact relative to market differentiation, the main effect is increased competition and lower profits for both firms. When a conquesting modification has higher impact, the business stealing advantage (i.e., gaining customers from the competitor) overshadows the disadvantage of increased competition. As a result, unless a downstream firm identifies a high-impact conquesting modification, it is generally preferable to focus on building value with core customers.

The equilibrium strategy for a vendor of two-sided information is to sell the complete packet of information to both downstream firms. Interestingly, this is the case 
even though both firms ultimately implement only retention modifications (they possess the information on conquesting modifications but choose not to use it). In other words, the conquest-facilitating information is passive in the sense that the downstream firms do not use it. This points to a strategic aspect of information markets: It is possible for the vendor to make strictly greater profits by including conquesting information in the packet, even though this information will not be used in equilibrium by the downstream firms. The intuition for this stems from the fact that the price charged for the information depends not only on the equilibrium profits of the downstream firms, but also on the situation faced by an individual firm were it not to buy the information packet. The availability of conquesting information puts a potential nonbuyer of information in a worse situation because of the threat that the buyer will implement the conquesting modifications and more adversely affect the nonbuyer. This threat allows the vendor to extract a higher price from both buyers by selling complete packets of information. This highlights the passive power of information and demonstrates that information can have value even when it is not used.

With one-sided information, the optimal selling strategy involves selling to only one firm, the firm for which the modifications are retention type. Because conquesting modifications of low impact are profitreducing for downstream firms, we expect this result when one-sided information identifies low-impact modifications. The analysis shows that even when the information identifies high-impact modifications (and positive profits are generated by selling the information for conquesting purposes), the vendor is strictly better off by targeting his information to the firm for which the modifications are retention type. An interesting aspect of the selling contract for one-sided information is that it is self-enforcing in the sense that a contractual guarantee of exclusivity is unnecessary for the vendor to credibly sell the information to a single firm. This is because once the focal firm uses the onesided information to implement the retention modification, its competitor does not have an incentive to implement a counteracting conquesting modification (even if the information were available for free).

\subsection{Related Research}

A large body of research on product modifications deals with the measurement of consumer utility for product attributes. An important methodology is conjoint analysis, which measures consumer preferences for products as bundles of attributes (see Green and Srinivasan 1990 and Green and Kreiger 1989). ${ }^{5}$ We focus on the competitive effects of product modifications and the problem faced by vendors of information that facilitates these modifications.

There is a stream of research that examines the selling of information in financial markets. A basic characteristic of financial markets (stocks, bonds, options, or foreign currency) is the exchange of money for an instrument that has uncertain value. The role of information in these markets is to provide a more precise estimate for the value of the instrument. The owner of financial information benefits by trading with investors who have less precise knowledge of the instrument's value. Grossman and Stiglitz (1980) have argued that because information is costly, market prices cannot perfectly reflect the available information because if it did, sellers of information who invested to obtain information would receive no compensation. Admati and Pfleiderer (1986, 1988, 1990) examine the sale of financial information and demonstrate that externalities between buyers affect the value of information and how broadly a given packet of information should be sold. Certain types of marketing information (consultants' reports on certain categories or new market opportunities) may also allow a manufacturer to improve the precision with which it understands its customers. For example, Sarvary and Parker (1997) examine the competition between two sellers of noisy information. They show that the relationship between the information products of the sellers can often lead to a seller being better off facing competition than if she were a monopolist.

Our characterization of the role of syndicated marketing information is different from this stream of research. We focus on the role of syndicated information used by brand managers in product markets. The primary use of this type of information is to identify relationships between brand loyalty and the preferences, behaviors, and habits of consumers. These relationships are used to identify product modifications that

\footnotetext{
${ }^{5} \mathrm{~A}$ complete review of product design models is provided in Lilien et al. (1992).
} 
provide additional value to consumers in a targeted fashion (i.e., benefits that are more valued by some customers in the market than others). Shaffer and Zettelmayer (1999) have also examined the role of information that adds value based on consumer loyalty in the context of a distribution channel relationship. In a model of two manufacturers and a common retailer, they analyze how the division of profits in the channel might be affected by the provision of information relevant to loyal or nonloyal consumers of a manufacturer.

There are some important differences in analyzing the sale of syndicated marketing data (versus sale of financial information). First, financial markets are efficient in reflecting the information that traders possess: Uninformed traders learn, and can adjust, their behavior relatively quickly. In contrast, product modifications are planned and implemented over a longer time period, and the advantage of a modification often obtains from the time needed by a competitor to react. Second, the value of financial information does not typically differ across buyers in the industry. In the case of product modification information, the value of the information can vary substantially across potential buyers. For example, information that facilitates a retention modification for one firm will facilitate a conquesting modification for a competing firm. Thus a significant part of our analysis is dedicated to understanding how downstream firms use information once they possess it. We show how a vendor takes this into account in choosing her strategies.

Raju and Roy (1997) considered the value of information to firms that are of different sizes. Our article deals with buyer firms with different valuations for the information, not because they are of different sizes (firms in our framework are ex-ante symmetric), but because information allows a manufacturer to differentially add value based upon customer loyalty. ${ }^{6}$

${ }^{6}$ Three other papers that model information are Pasa and Shugan (1996), Villas-Boas (1994), and Soberman (1997). Pasa and Shugan model expertise as a marketer's ability to create and interpret information about demand, and they are concerned with characterizing the value of such information. Villas-Boas studies the transmission of strategic information between rival firms through a common advertising agency. Soberman models information about media habits of category users, which allows a firm to send messages to category users more efficiently.
This article proceeds as follows. The following section presents the model. In $\S 3$, we analyze how conquesting and retention product modifications affect the downstream competition between the firms. This sets the stage for the main analysis in $\S 4$, where we discuss the vendor's equilibrium selling strategies. In $\S 5$, we discuss the managerial implications, and we conclude in $\S 6$.

\section{The Model}

The model consists of an information vendor and two potential buyers of information who compete in a downstream product market. ${ }^{7}$ The game has two stages. The first stage is the selling of information by the vendor to the downstream firms. After the firms have decided whether or not to purchase the information, they decide whether or not to make modifications to their products. They then compete in the downstream product market by simultaneously setting prices. Finally, consumers decide to buy at the firm that gives them greater surplus. We begin by describing the downstream product market.

\subsection{The Downstream Market Before Product Modifications}

The potential buyers of information are two firms denoted by $i=1,2$. The information, if purchased by the firms, provides them with the knowledge to make modifications to their existing products. We use a linear spatial market in which the products of firms are differentiated with respect to a primary attribute. The market is of unitary length, and consumers are uniformly distributed along the market with unit density. Each consumer buys at most one unit of the product. The two firms are located at either end of the market. A product located at the same location as a consumer

\footnotetext{
${ }^{7}$ The context for our article is information vendors such as ICOM, Yankelovich, or R. L. Polk, which have different data collection procedures and offer syndicated services that are not easily substitutable. This provides relevance to the single vendor analysis. Furthermore, the single vendor assumption allows us to focus on competition in the buyer market and to highlight the competitive externalities that product modifications create.
} 
corresponds to that consumer's ideal product, and consumers incur a disutility for consuming a product that is not at their ideal point. Let us first consider the consumer's surplus before any product modification. For a consumer located at $x$ (the distance from the left endpoint), the following quasi-linear surplus function represents the surplus delivered by the unmodified product of Firms 1 and 2, respectively:

$$
\begin{gathered}
C S_{1}=R-p_{1}-x t, \\
C S_{2}=R-p_{2}-(1-x) t .
\end{gathered}
$$

Here $t$ is the travel cost parameter that represents the psychological preference cost (or the per-unit distance disutility) of the consumer for not consuming her ideal product. ${ }^{8} R$ is the reservation value for the unmodified product, and $p_{1}, p_{2}$ represent the prices to consumers for the two products.

\subsection{Product Modifications}

Next, suppose that firms have information that enables them to perform value-adding modifications to their products. The surplus functions with the modifications will be

$$
\begin{gathered}
C S_{1}=R+v_{1}(x)-p_{1}-x t, \\
C S_{2}=R+v_{2}(x)-p_{2}-(1-x) t .
\end{gathered}
$$

The function $v_{i}(x)$ represents the added value that a consumer at $x$ will obtain from firm i's modification. Note that this incremental benefit is a function of the consumer's location or relative preference for the two products. If $v_{i}(x)$ is decreasing in $x$, then the modification provides the firm's loyal consumers with a greater incremental benefit than the consumers who are less loyal. This is a characterization of a retention modification. In contrast, if $v_{i}(x)$ is increasing in $x$, then the modification provides the firm's loyal consumers with less incremental benefit than consumers who are loyal to the competing firm's product. This is a characterization of a conquesting modification. ${ }^{9}$

\footnotetext{
${ }^{8}$ Although we assume linear travel costs, the main insights of the article also hold for travel costs that are quadratic in distance.

9The term "conquesting" is from Colombo and Morrison (1989), who use it in the context of a brand-switching model. Note also that the idea of retention and conquesting is also related to Hauser and Shugan's (1983) conceptualization of defensive and offensive marketing strategies.
}

We use the functional form $v_{1}(x)=\beta(1-x) ; v_{2}(x)$ $=\beta x$ to represent the effect of retention modifications on the surplus functions for the products of Firms 1 and 2 , respectively. ${ }^{10}$ Figure 1 shows the consumer surplus function for a retention modification implemented by Firm 1. Note that in this formulation, $\beta$ is the impact of the modification; i.e., a greater $\beta$ implies that the modification is more valuable (to all consumers but differentially so). In the same vein, $v_{1}(x)=\beta x$; $\nu_{2}(x)=\beta(1-x)$ represents the effect of conquesting modifications for each firm. Figure 2 shows the consumer surplus function for a conquesting modification implemented by Firm $1 .^{11}$

${ }^{10}$ In addition to the linear value function, the results are robust to
the entire family of concave and convex nonlinear specifications of
the value function in the quadratic form. Analysis of a nonlinear
specification of the value function is shown in the appendix. A full
analysis is available from the authors on request.
${ }^{11}$ These modifications introduce the idea that a product modification
can endogenously create vertical differences in a market where con-
sumers a priori are horizontally differentiated. In other words, after
the modification is implemented, consumers at different points in

Figure 1 Effect of a Retention Modification

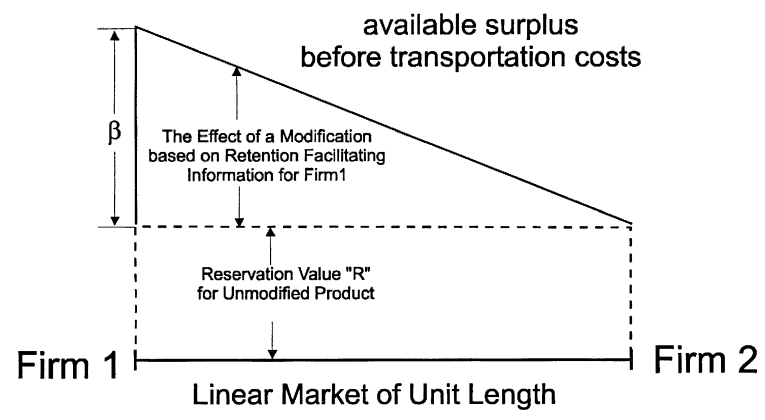

Figure 2 Effect of a Conquesting Modification

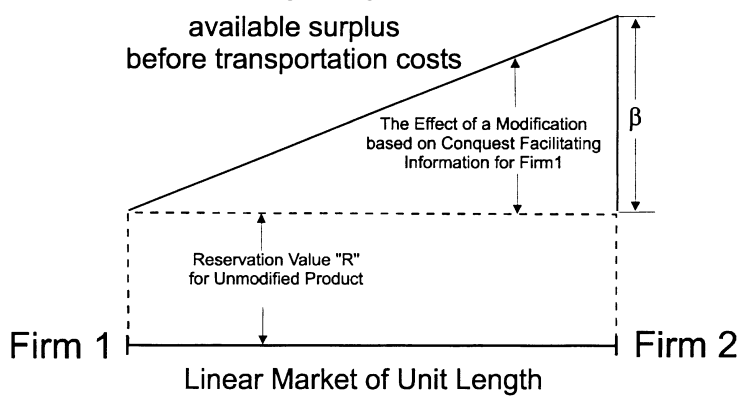

Marketing Science/Vol. 19, No. 3 Summer 2000 


\subsection{The Interpretation of Information and Product Modification}

Because the sloped line, $v_{i}(x)$, represents what information facilitates in this framework, it is important to understand the economic meaning of the slope and how it represents the impact of information. In the pain reliever example discussed earlier, we could think of Motrin as being at one end of the linear market and Advil as being at the other. The sloped function $v_{i}(x)$ represents the effect of a change to the product that is highly correlated with loyalty to one of the two products. In the pain reliever context, it is possible for the brand manager of Motrin to use the information from the ICOM database (that loyalty to Advil is highly correlated with headache relief) to implement a program that underlines the advantages of Motrin for relief from headaches. This is a prototypical conquestingtype modification because it will have a greater effect on loyal users of Advil than on the loyal users of Motrin. In contrast the information from the database can also be used to highlight the efficacy of Motrin for relief of backaches or menstrual cramps. This is a retention-type modification.

The model assumes that the characteristics of the information are fixed before the information contracting begins. This is equivalent to the assumption that the information costs are sunk at the time of contracting. This assumption is consistent with the institutional reality of the syndicated data vending industry. In general, the tracking systems of large syndicated data vendors such as ICOM and R. L. Polk are not tied to the needs of any single client firm. ICOM, for example, maintains a database of more than 20 million households, and it conducts mailings twice per year to more than 10 million households (Smith 1998). Occasionally ICOM adds tailored questions at the request of important clients such as P\&G or J\&J. But, in the main, the costs of surveying and maintaining the database are sunk costs.

Next the model assumes that the information vendor has knowledge of the value of the information to the downstream buyers. This assumption captures the fact

the market will have different willingness to pay (as in Moorthy 1988 or Shaked and Sutton 1982). that firms such as ICOM have extensive knowledge of the research information needs of their clients and the particular industries that they serve. Vendors often organize their sales force based on sectors such as pharmaceuticals (OTC), finance, automotive, packaged goods, insurance, and tobacco and have category specialists within each sector. ICOM specialists have regular meetings with their key clients to better tailor the surveys to the needs of the marketplace. Furthermore, client firms often require the services of ICOM to help them in judging the value of potential correlations and the likelihood of a proposed program being successful. This provides additional opportunities for learning about a client's business.

We now describe the first stage of the game that involves the selling and pricing of the information product.

\subsection{Stage One: The Information Vendor Decisions}

One-Sided Information. With one-sided information, the downstream firms are not symmetric. As in the Coors Light example, for one firm (Coors), the information points to modifications that will increase value for its loyal customers (retention modifications), whereas for the other firm (Miller) the same information will facilitate a conquesting modification. The vendor has to decide whether her strategy is to sell to only one firm or to sell to both firms.

If the vendor opts to sell her information to just one firm, she must also decide to which of the two firms she should sell it (the firm for which the information is retention facilitating or the firm for which it is conquesting facilitating). As shown in Figure 3, if the first firm rejects the offer, the vendor has the option of offering the information to the second firm. When the information vendor sells to only one firm, we must distinguish between the cases of offering the information to Firm 1 and Firm 2 because the firms have asymmetric valuations for it. Note that under the strategy of selling to one firm, say Firm $i$, the information vendor's pricing strategy consists of a price offer of $P_{x i}$ to Firm $i$ and a price offer $P_{y i}$ to Firm $j$ (if Firm $i$ rejects the vendor's offer).

Furthermore, when the vendor decides to sell to just one firm, we also investigate whether it is necessary for the vendor to offer a guarantee of exclusivity (i.e., a 
contractual commitment not to sell the information to the firm that has not purchased the information). As shown in Figure 3, when the information vendor chooses an exclusive strategy, she does not sell the information to the second firm if the first firm accepts the offer. Conversely, if an offer is rejected, the vendor can sell the information to the second firm. It is often the threat of being in the position of a firm without the information that makes buying the information attractive. In general, exclusive contracts are legally binding and have sanctity in a court of law. ${ }^{12}$ But the critical point that our analysis highlights is that when the vendor finds it optimal to sell to only one firm, a guarantee of exclusively is unnecessary. Finally, note that under the strategy of selling to both firms, the offer is made simultaneously to the firms. The game tree for the information-selling stage with one-sided information is shown in Figure 3.

The timing of the game can be summarized as follows.

Step 1. The information vendor chooses the selling approach (to one or to both firms).

Step 2. If the vendor chooses to sell to one firm, he decides whether to sell the information to facilitate retention or conquesting modifications.

Step 3. The information vendor sets prices for information conditional on the selling approach and target firm she has chosen. ${ }^{13}$

Step 4. Firms make decisions on whether or not to purchase the information conditional on the terms and price offered by the information vendor.

Two-Sided Information. In contrast to one-sided

\footnotetext{
${ }^{12}$ In the United States, exclusive contracts are subject to a rule of reason, and in Canada the only antitrust challenge to an exclusive contract is that it constitute an "abuse of dominant position." See Continental TV Inc. v. GTE Sylvania Inc., U.S. 36 (1977) and Preston (1994) and the Director of Investigation and Research v. NutraSweet (1990), 32 C.P.R. (3d) 1 regarding the legality and enforceability of exclusivity contracts.

${ }^{13}$ Under the approach of selling to only one firm, the information vendor sets the price for the second firm after the first firm rejects the offer (there is no reason why the vendor should be forced to set a price for the second firm before the first firm makes its decision). Analytically, however, there is no difference between this structure and one in which the vendor chooses both prices prior to the first firm's decision.
}

information, two-sided information has the potential to facilitate modifications that add value to consumers who are on both sides of the loyalty spectrum. Thus the information that Motrin's usage is highly correlated with sufferers of backache and menstrual cramps and the usage of Advil's is correlated with headache relief can potentially be used by both firms to add value to either or both sides of the market. The greater complexity of two-sided information means more selling options for the vendor. Only the strategy of selling to a single firm is simple because the vendor will always offer the complete set of information. ${ }^{14}$ When information is sold nonexclusively, the vendor must decide whether to sell complete information packets (i.e., both retention and conquesting information) or limited information packets (i.e., either retention or conquesting information, but not both). ${ }^{15}$ The game tree for the first stage of the game with two-sided information is shown in Figure 4.

The timing is as follows:

Step 1. The information vendor chooses selling approach (one or to both firms).

Step 2. Assuming the vendor decides to sell nonexclusively, she must decide whether to sell the complete or limited packet of information.

Step 3. The information vendor sets prices for information conditional on both the selling approach and packets he has decided to offer.

Step 4. Firms make decisions on whether or not to purchase the information and then decide on the type of modifications to implement using the information. Note that a firm is not obligated to implement the modifications because it has purchased the information. For example, a firm can buy both retention and conquesting information but use only one type of information in equilibrium.

\footnotetext{
${ }^{14}$ The vendor could offer a limited packet of information exclusively, but this strategy is strictly dominated: The actions facilitated by a limited packet are a subset of the actions made possible with a complete packet.

${ }^{15}$ It is possible for a vendor to sell a complete information packet to one firm and a limited packet to the other. This "asymmetric" packaging strategy, however, is strictly dominated by the strategy of selling "symmetric" information packets. Similarly, the strategy of selling retention information to one firm and conquesting information to the other is dominated.
} 
Figure 3 Stage 1: Game Tree for One-Sided Information

Assume the Indicated Modifications are Retention-Type for Firm 1 and Conquesting-Type for Firm 2

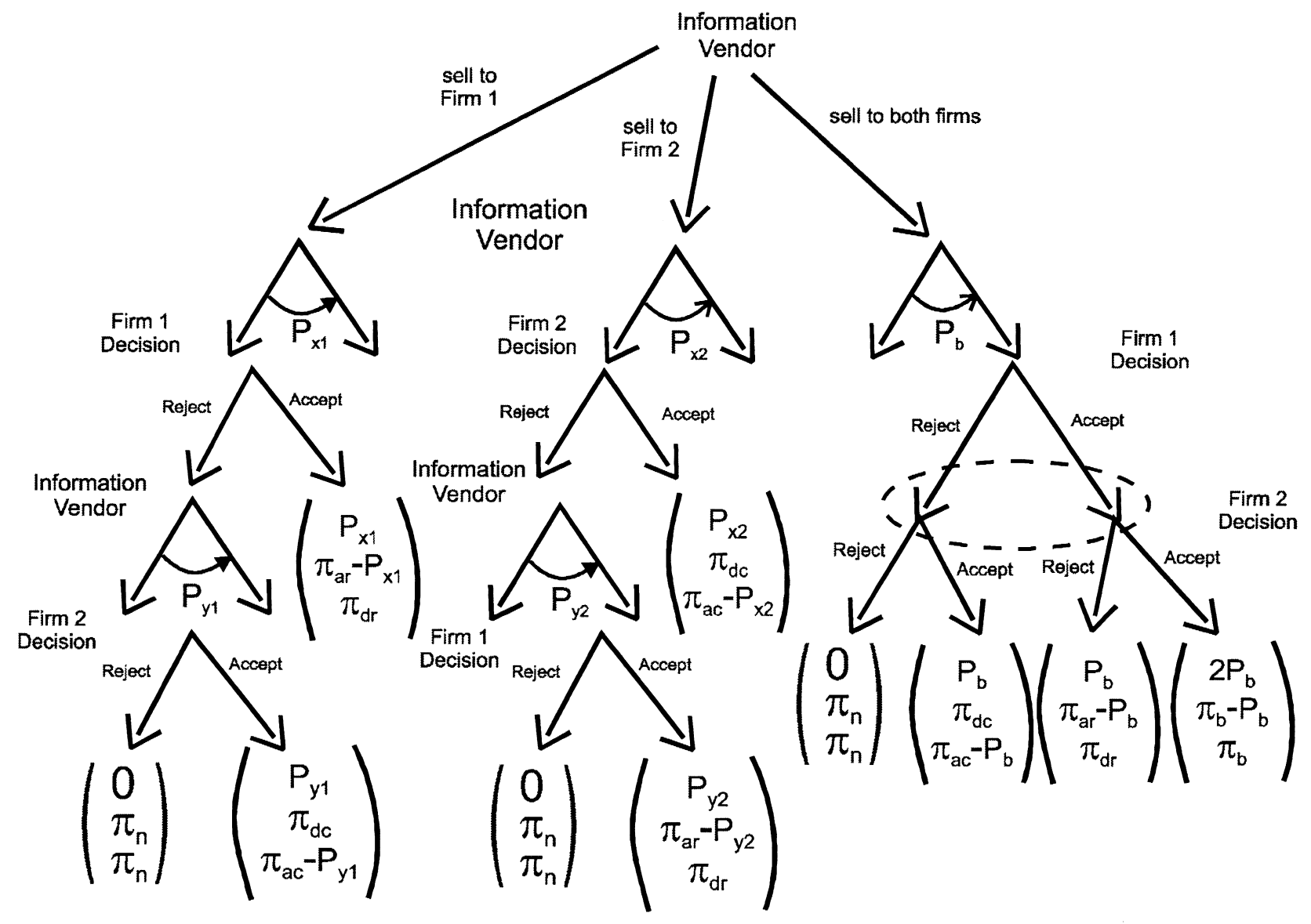

\begin{tabular}{|lllll|}
\hline Legend & & Firm Profits when both have information & $\pi_{\mathrm{b}}$ \\
Firm 1 profit with information when Firm 2 does not & $\pi_{\mathrm{ar}}$ & Vendor Price such that both firms will buy & $P_{\mathrm{b}}$ \\
Firm 1 profit without information when Firm 2 has it & $\pi_{\mathrm{dc}}$ & Vendor Price if only Firm 1 buys & $\mathrm{P}_{\mathrm{x} 1}$ \\
Firm 2 profit with information when Firm 1 does not & $\pi_{\mathrm{dr}}$ & Vendor Price if only Firm 2 buys & $\mathrm{P}_{\mathrm{x} 2}$ \\
Firm 2 profit without information when Firm 1 has it & $\pi_{\mathrm{ac}}$ & Vendor Price to Firm 2 if Firm 1 rejects 1st offer & $\mathrm{P}_{\mathrm{y} 1}$ \\
Firm profits when neither have information & $\pi_{\mathrm{n}}$ & Vendor Price to Firm 1 if Firm 2 rejects 1st offer & $P_{\mathrm{y} 2}$ \\
\hline
\end{tabular}


Figure 4 Stage 1: Game Tree for Two-Sided Information

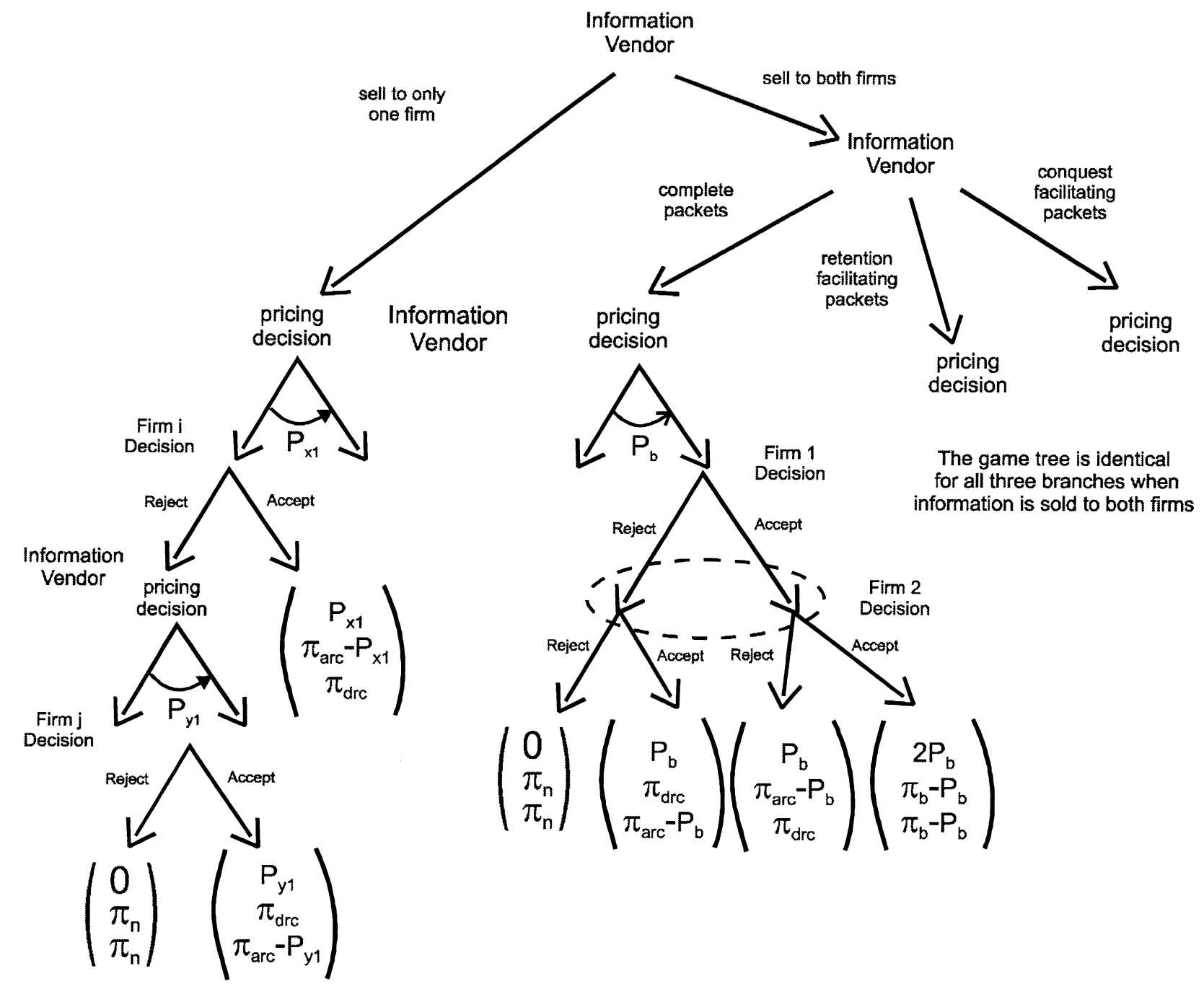

\section{Legend}

Firm Profits when both have information

$\pi_{\mathrm{b}}$

Firm i profit when only it has use of the information $\pi_{\text {arc }}$ Vendor Price if both firms buy the information $P_{b}$ Firm $\mathrm{j}$ profit when only it has use of the information $\pi_{\mathrm{drc}}$ Vendor Price if only 1 firm buys the information $P_{\mathrm{x} 1}$ Firm profits when neither have information

$\pi_{n} \quad$ Vendor Price for Firm $j$ if Firm i rejects the offer $P_{y 1}$

In Figures 3 and 4, three-dimensional outcome vectors describe the payoffs for the information vendor, Firm 1, and Firm 2 for each decision combination. These payoffs are determined based on the modifica- tions implemented by each firm and competition in the product/service market. In Figure 3, the downstream profits are denoted by $\pi_{y z}$, where $y=a, d, b, n$ denotes the circumstance of the firm in question ( $a$ denotes 
advantage, implying that the firm has an advantage due to possessing the information when its competitor does not; $d$ denotes disadvantage; $b$ denotes that both firms have the information; and $n$ denotes that neither firm has purchased the information) and $z=r, c$ relates to the type of modification that can be implemented by the information ( $r$ and $c$ refer to the sale of retention and conquesting information, respectively). In Figure 4, the subscript $r c$ on the exclusive strategy profits implies that the packet contains information that facilitates both retention and conquesting modifications.

\subsection{Stage Two: The Downstream Firm Decisions}

The second stage of the game (which occurs after the information-selling phase) involves decisions by firms and consumers. In this stage the two downstream firms simultaneously choose prices contingent upon the outcome of the information-selling phase.

The demand faced by Firms 1 and 2 are $x_{1}$ and $x_{2}$, respectively, which are determined by the incentive compatibility constraint $\left(C S_{1}=C S_{2}\right) .{ }^{16}$ The profit functions for the two firms before any payments for information are

$$
\begin{aligned}
& \pi_{1}=\left(p_{1}-c\right) x_{1} \\
& \pi_{2}=\left(p_{2}-c\right) x_{2}
\end{aligned}
$$

where $p_{1}$ and $p_{2}$ are the prices chosen by each firm and $c$ is the marginal cost for each unit of the product delivered. After the information market has closed, firms decide which (if any) modifications to make to their product. After the firms implement their modification strategies, they simultaneously choose the market price to maximize profits.

Before examining the competition given product modification information, we briefly discuss the base case of a market without information (i.e., no information is used by either firms). This means that the two firms compete with unmodified products that deliver consumer surplus as in (3) and (4). Simple computations yield equilibrium prices of $p_{1 n}=p_{2 n}=t+$

\footnotetext{
${ }^{16} \mathrm{We}$ focus the analysis on the interesting case where there is competition between the two firms with unmodified products to begin with. This implies that $R>3 t / 2+c$.
}

$c$ and equilibrium profits of $\pi_{1 n}=\pi_{2 n}=t / 2$. This case is the benchmark to understand the effect of product modifications on downstream competition.

\section{Downstream Competition Given Product Modifications}

It is important to first analyze the impact of the different types of modifications on downstream competition because this provides insights into the selling strategies of the vendor that are analyzed in $\$ 4$. In this section we ask the question: How would price competition between the firms evolve given that they are endowed with the ability to make certain types of modifications? Instead of presenting the analysis for all the possible scenarios of competition with product modifications, we concentrate on those that are needed for $\S 4$, where we analyze the vendor's choice of contracting strategies for one-sided and two-sided information. Accordingly, we examine three cases of downstream competition that pertain to when firms have the information to implement (1) retention modifications only, (2) conquesting modifications only, and (3) both retention and conquesting modifications. Because we are interested in analyzing whether or not the vendor should offer exclusive contracts, we also examine each of these three scenarios for the case of only one firm having the information and for the case of both firms having it.

\subsection{Only Retention Modifications}

Suppose only one firm (say Firm 1) has retention-type information and implements the modification; the incentive compatibility constraint is $\beta\left(1-x^{*}\right)-p_{1}-$ $t x^{*}=-p_{2}-t\left(1-x^{*}\right)$. This leads to the demand functions for Firms 1 and 2, respectively, as $x_{a r}=x^{*}=(\beta$ $\left.+t-p_{1}+p_{2}\right) /(\beta+2 t)$, while $x_{d r}=\left(1-x_{a r}\right)$. Solving for the equilibrium prices and profits, we obtain

$$
\begin{gathered}
p_{a r}=\frac{2 \beta}{3}+t+c, p_{d r}=\frac{\beta}{3}+t+c ; \\
\pi_{a r}=\frac{\left(t+\frac{2 \beta}{3}\right)^{2}}{\beta+2 t}, \pi_{d r}=\frac{\left(t+\frac{\beta}{3}\right)^{2}}{\beta+2 t} .
\end{gathered}
$$

Note that $\pi_{a r}$ is strictly greater than $t / 2$, implying that 
a firm with the information to implement a retention modification will always choose to do so.

When both firms have retention-type information and implement the modifications, the demand functions of the two firms are given by the (incentive compatibility) condition $\beta\left(1-x^{*}\right)-p_{1}-t x^{*}=\beta x^{*}-p_{2}$ $-t\left(1-x^{*}\right)$. This yields Firm 1's demand function as

$$
x_{1 b r}=x=\frac{\beta+t-p_{1}+p_{2}}{2(\beta+t)},
$$

while Firm 2's demand function is $x_{2 b r}=(1-x)$. The equilibrium prices and profits are

$$
p_{b r}=\beta+t+c, \pi_{b r}=\frac{t+\beta}{2} .
$$

Note that $\pi_{b r}$ is strictly greater than $t / 2$ and $\pi_{d r}$, implying that both firms will implement retention modifications if they have the ability to do so.

To summarize, the impact of the retention modification (reflected by the magnitude of $\beta$ ) affects the equilibrium prices and profits in the same manner as the differentiation parameter $t$. In this sense, retention modifications act to increase the "effective" differentiation between firms and cause prices to rise. Interestingly, the strategic effect of a retention modification (in increasing equilibrium prices of both firms in the market) is evident even when only one firm implements the modification. The expression in (7) shows that prices of both firms go up unambiguously when only one firm implements a retention modification. The firm implementing the modification is able to protect its loyal consumers and increase its market share even though it charges a higher price. This induces the competing firm to respond by strategically raising its price. Thus the firm implementing the modification confers a positive externality on its competitor, thereby allowing it to charge higher prices. When both the firms implement retention modifications, this positive externality is even stronger. The competition between the firms is less intense, and equilibrium prices (for both firms) are higher, than when only one firm implements a retention modification.

\subsection{Only Conquesting Modifications}

Similar to retention modifications, we consider two cases: the first where only one firm possesses conquesting information, and the second where both firms do.
Equilibrium When One Firm Has ConquestingType Information. In contrast to retention modifications, the effect of conquesting modifications depends on their impact. This is because conquesting modifications of sufficiently high impact enable a firm to attract all consumers from the competitor's half of the market.

Let us first consider the case where the modifications are of sufficiently low impact that the competitor continues to operate. This happens in the model as long as $\beta / t<1.5$. The incentive compatibility constraint is $\beta x-p_{1}-t x^{*}=-p_{2}-t\left(1-x^{*}\right)$, which yields the demand functions for Firms 1 and 2 of $x_{a c}=x^{*}=\left(p_{2}\right.$ $\left.-p_{1}\right) /(2 t-\beta)$ and $x_{d c}=\left(1-x_{a c}\right)$. The equilibrium prices and profits are $p_{a c}=t+c-(\beta / 3), p_{d c}=t+$ $c-(2 \beta / 3)$, and $\pi_{a c}=t-(\beta / 3)^{2} /(2 t-\beta), \pi_{d c}=t-$ $(2 \beta / 3)^{2} /(2 t-\beta)$, respectively.

When $\beta / t<1.5$, conquesting modifications reduce the effective differentiation in the market and lead to increased competition. To see this, notice that consumer surplus (from Firm 1) can be rewritten as $R-$ $(t-\beta) x-p_{1}$. The modification effectively reduces the consumer preference cost from $t$ to $(t-\beta)$, making it more attractive for consumers anywhere in the market (including consumers close to Firm 2) to purchase at Firm 1. Because Firm 1 now threatens customers close to Firm 2, the strategic response of Firm 2 is to reduce its price and protect its customers. Thus, by implementing a conquesting modification, Firm 1 confers a negative externality on Firm 2. In fact, when $\beta / t<1.5$, conquesting modifications also result in reduced profits for the implementing firm versus the base case because the benefits (in terms of increased demand) provided by the modification are more than negated by the fierce price competition. Consequently, even if a firm has the unilateral ability to implement a conquesting modification, it will never do so when $\beta / t<1.5$.

When $\beta / t \geq 1.5$, conquesting modifications have another important effect. They give the implementing firm (Firm 1) the ability to poach its competitor's loyal customers and to monopolize the market. The economic meaning of this is that the business stealing effect of the modification (the ability to attract the competitor's customers) dominates its competition increasing effect. Nevertheless, when Firm 2 is forced from the market, it continues to affect the pricing decisions of Firm 1 (because it will re-enter the market 
when Firm 1's price is too high). When $\beta / t \in\{1.5,2\}$, Firm 1 sets price at $p_{a c}=c+\beta-t$, and when $\beta / t \in$ $\{2,3\}$, Firm 1 prices at $t+c$. These prices are low enough to keep Firm 2 out of the market, and they serve to maximize profit for Firm 1 . When $\beta / t>3$, Firm 1 has the ability to keep Firm 2 out of the market. Yet it is motivated to set high prices (to capture the significant surplus created by the modifications), and this allows Firm 2 to operate with positive demand but from the consumers that are close to Firm 1 in the attribute space. We label this as a "backdoor" effect that enables Firm 2 to sell to consumers close to Firm 1. Similar to the situation when $\beta / t<1.5$, the modification acts in a direction opposite to the existing differentiation $(t)$. However, except in conditions where $\beta /$ $t \in\{2,3\}$, the equilibrium prices now increase in $\beta$. More interestingly (and contrary to what one would expect), prices actually decrease with higher differentiation. Once a modification is powerful enough such that Firm 1 has the ability to monopolize the market, greater differentiation is "bad" in the sense that it increases the cost of attracting the customers who are far away (i.e., lower prices have to be charged if distant consumers are to be attracted).

Firm 1's profit $\left(\pi_{a c}\right)$ after implementing the modification is $\beta-t$ when $\beta / t \in\{1.5,2\}, t$ when $\beta / t \in\{2$, $3\}$, and $(2 / 3 \beta-t)^{2} /(\beta-2 t)$ when $\beta / t>3$. Because these profits are strictly greater than the base case profit, a firm with the ability to implement conquesting modifications will always do so when $\beta / t>1.5$. The resulting profit for Firm $2\left(\pi_{d c}\right)$ in these conditions is 0 when $\beta / t \in\{1.5,3\}$ and $(1 / 3 \beta-t)^{2} /(\beta-2 t)$ when $\beta /$ $t>3$.

Equilibrium When Both Firms Have ConquestingType Information. When both firms implement conquesting modifications, the overall pattern of results is similar to the previous case when only one firm implements the modification. As before, equilibrium prices and profits $(t-\beta+c$ and $(t-\beta) / 2$, respectively) are lower than the base case when the modification has relatively low impact (i.e., when $\beta / t<1$ ). The dominant strategy for a firm is not to implement the modification (independent of the competitor's product strategy). Thus, the firms will choose to market unmodified products despite having the information to implement conquesting modifications.
However, for $\beta / t>1$, in equilibrium, a situation of market reversal occurs in which consumers close to Firm 1 buy at Firm 2 and those close to Firm 2 buy at Firm 1. Once again, the insights are similar to the case when only one firm has the ability to implement modifications. Here, conquesting modifications are powerful enough to allow each firm to attract the competitor's customers. Consequently equilibrium prices and profits are increasing in $\beta$. Thus, when the modifications are of sufficiently high impact, it is possible that firms might actually implement the modifications despite their competition-increasing character. ${ }^{17}$

In summary, this section illustrates the differences between the effects of retention and conquesting modifications. Retention modifications have the singular effect of increasing differentiation in the market and thereby causing prices to rise. In contrast, the effect of a conquesting modification depends on the impact of the modification relative to the level of market differentiation. Relatively low impact conquesting modifications lead to increased competition and lower profits for the firms. Consequently, firms will unilaterally choose to not implement these modifications even when they have knowledge to do so. However, higher impact conquesting modifications can give firms the compensating benefit of attracting the customers of competition. This can result in situations of market dominance (when only one firm implements the modification) or market reversal (when both firms implement conquesting modifications or when one firm implements high impact conquesting modifications). In these situations, the positive relationship between $\beta$ and profits can motivate firms to implement these modifications.

\footnotetext{
${ }^{17}$ We find that when $\beta / t \in\{1,1.5\}$, each firm unilaterally prefers not to implement the modification regardless of whether its competitor implements the modification because the resulting price competition is too intense. However, when $\beta / t \in\{1.5,2\}$, the relative impact of the modification is large enough to give firms the incentive to implement the modification independent of the competitor's strategy. The downstream firms find themselves in a quintessential Prisoners Dilemma because the decisions of both firms to implement the modifications lead to profits that are lower than the base case. Finally, when the relative impact of the modification is very large $(\beta / t>2)$, both firms will implement modifications, but the Prisoners Dilemma situation no longer exists. In this range, the conquesting modifications are powerful enough that $\pi_{b c}$ is greater than the base case profits.
} 


\subsection{Both Retention and Conquesting Modifications}

The analysis of $\S \S 3.1$ and 3.2 is restricted to situations where the firms have the ability to implement either retention or conquesting modifications (but not both). This allows us to understand the pure effects of retention or conquesting modifications. However, when two-sided information is available, it is possible for the downstream firms to implement both retention and conquesting modifications simultaneously. In this section, we derive the equilibrium strategies for firms that have the ability to implement both retention and conquesting modifications (denoted by the subscript $r c$ ). This analysis is important to understand the contracting strategy for two-sided information.

Referring back to the pain reliever example, the analysis of this section pertains to a situation where the information possessed by each firm indicates not only Motrin's perceived superiority for backache and menstrual cramp relief, but also Advil's perceived superiority for headache relief. As before, we first consider the case where only one firm has the information.

Only One Firm Has Both Retention and Conquesting Information. A focal firm with both retention and conquesting information has the following options. It can implement only a retention modification, only a conquesting modification, or both. From $\$ \S 3.1$ and 3.2, we know the profits associated with the implementation of retention or conquesting modifications alone. Therefore, we need to analyze only the case of simultaneous implementation of retention and conquesting modification. When Firm 1 implements both types of modifications, the incentive compatibility condition that determines the demands of the firms is $\beta-p_{1}-t x^{*}=-p_{2}-t\left(1-x^{*}\right)$. The Nash equilibrium of the downstream market for the range $\beta / t<3$ is

$$
\begin{aligned}
p_{1} & =c+t+\frac{1}{3} \beta, p_{2}=c+t-\frac{1}{3} \beta \\
\pi_{a r c} & =\frac{(\beta+3 t)^{2}}{18 t}, \pi_{d r c}=\frac{(\beta-3 t)^{2}}{18 t} .
\end{aligned}
$$

When $\beta / t \geq 3$, the equilibrium prices are $p_{\text {arc }}=\beta-t$ $+c ; p_{d r c}=c$, and the equilibrium profits $\pi_{a r c}=\beta-t$; $\pi_{d r c}=0$. We now compare $\pi_{a r}, \pi_{a c}$ and $\pi_{a r c}$ to identify the equilibrium modification strategy for a firm that has the ability to implement both retention and conquesting modifications in Result 1. All proofs are in the appendix, which is posted on the Marketing Science website (www.smeal.psu.edu/MktgSciJournal).

Result 1. A firm that has the unilateral ability to implement both retention and conquesting modifications:

(a) Will choose to implement only a retention modification when $\beta / t<\sqrt{3}$,

(b) Will choose to implement both retention and conquesting modifications when $\beta / t \geq \sqrt{3}$.

Result 1 leads to interesting generalizations about the strategies of the focal firm. When modifications have low impact (i.e., $\beta / t<\sqrt{3}$ ), retention modifications alone are the optimal strategy. In $\$ 3.2$, we saw that the main effect of low-impact conquesting modifications was to reduce effective differentiation and create ruinous price competition. This effect exists even when the focal firm can implement retention modifications at the same time. Note that when a firm implements both retention and conquesting modifications simultaneously, it is identical to an overall quality improvement for all consumers in the market. ${ }^{18}$ Thus, a further insight is that when the impact of modifications is small, segment-specific improvements are more attractive than overall improvements.

When modifications are of high impact $\beta / t \geq \sqrt{3}$, the firm implements both retention and conquesting modifications. In this range, the business stealing advantage of conquesting modifications compensates for the increased price competition that it creates. Because the simultaneous implementation of retention and conquesting modifications is equivalent to an overall quality improvement, the result also suggests that when modifications are of intermediate impact, overall improvements are superior to segment-specific (i.e., retention or conquesting) modifications.

As in the previous sections, the general pattern of results is that when the modifications have small impact relative to the level of differentiation, retention modifications tend to be more attractive. Only when modifications have high impact in relation to the level of differentiation do conquesting modifications become attractive.

\footnotetext{
${ }^{18}$ This obtains by summing the impacts of the modifications $\beta x$ and $\beta(l-x)$.
} 
Equilibrium When Both Firms Have Retention/ Conquesting Information. In this case again, each firm has three possible strategies in the normal form game: implement only retention modifications, implement only conquesting modifications, or implement both types of modifications. ${ }^{19}$ Table 3 shows the best response mappings for each of these three potential strategies.

Result 2. When both firms have the ability to implement retention and conquesting modifications, the unique Nash equilibrium is for both firms to implement retention modifications only.

This result establishes an important aspect of competition given product modification information. Although both firms have the knowledge to implement conquesting modifications, neither firm makes use of it. One might think that a firm (say Firm 1) could improve its performance by implementing both retention and conquesting modifications in response to a competitor's retention modifications. Firm 1's equilibrium demand increases: it can be shown that $x^{*}$ equals $(2 \beta$ $+3 t) /(3 \beta+6 t)$, which exceeds one half (the market share of Firm 1 when it responds with retention modifications alone). But, the positive externality of Firm 2 's retention modification is eliminated by the competitive effect of Firm 1's conquesting modification. Overall, the increase in price competition negates any

${ }^{19} \mathrm{~A}$ fourth strategy of not implementing any modifications is strictly dominated under all conditions.

Table 3 Best Response Summary for a Firm With the Ability to Make Both Retention and Conquesting Modifications

\begin{tabular}{lll}
\hline \multirow{2}{*}{ Competitors Action } & \multicolumn{2}{c}{ The Best Response } \\
\cline { 2 - 3 } Retention Modifications & \multicolumn{1}{c}{ Retention } & \multicolumn{1}{c}{$\beta / t>1.5$} \\
& Modifications & $\begin{array}{l}\text { Retention } \\
\text { Modifications }\end{array}$ \\
Conquesting & Retention & Retention and \\
Modifications & Modifications & $\begin{array}{l}\text { Conquesting } \\
\text { Modifications }\end{array}$ \\
Retention and & & Retention \\
Conquesting & Retention & Modifications \\
Modifications & Modifications & \\
\hline
\end{tabular}

benefit derived from higher demand. Consequently, a firm cannot improve its performance in this manner.

What is the intuition behind why conquesting modifications are not implemented? Recall from $\$ 3.2$ that conquesting modifications have the disadvantage of intensifying the competition between firms. It is only when conquesting modifications are of sufficiently high impact that their business stealing benefits (in terms of attracting the competitor's customers) can counterbalance the cost of increased competition. However, when both firms can implement retention and conquesting modifications, the business stealing benefit no longer has any "bite." This is because a retention modification implemented by a firm will nullify any business stealing advantage that might exist for its competitor. Therefore, when firms have both types of information, implementing the conquesting modification involves costs (of increased competition) but has no associated benefits.

The result also suggests that if firms have the knowledge to make modifications to their products that are segment specific, most of the observed modifications implemented in actual markets should be retentiontype modifications. ICOM's experience in selling syndicated information in consumer product categories is consistent with this suggestion. In the eight large FCMG categories in which ICOM operates, a majority of the programs conducted by the vendor for its clients focus on brand loyal users. Furthermore, there is also a suggestion that firms are unlikely to implement conquesting modifications unless they are convinced that the competitor is passive and cannot respond with a retention modification of its own.

\section{The Selling of Product Modification Information}

We now examine the main issue of the article. We analyze the information vendor's problem for two situations. In the first, she possesses one-sided information; in the second, she possesses two-sided information. In both situations, the vendor must decide whether to sell to only one or to both firms. Additionally in the case of two-sided information, she must also decide how to package the information. 


\subsection{Solving the Information Vendor's Game} We begin by discussing how the equilibrium profits of the information vendor are determined. First, we determine the maximum price under which both firms will buy the information. ${ }^{20}$ We define this as the nonexclusive price for the information.

Selling to Both Firms. Note that the profit from selling the information nonexclusively requires that both firms buy. In Figures 3 and 4, the following inequalities must be satisfied to ensure that both firms buy

$$
\begin{gathered}
\pi_{a}-P_{b} \geq \pi_{n} \wedge \pi_{b}-P_{b} \geq \pi_{d} \\
\Rightarrow P_{b} \leq \pi_{a}-\pi_{n} \wedge P_{b} \leq \pi_{b}-\pi_{d} .
\end{gathered}
$$

Rewriting this,

$$
P_{b} \leq \min \left(\pi_{a}-\pi_{n}, \pi_{b}-\pi_{d}\right) .
$$

The total revenue from the nonexclusive sale for the vendor is $2 P_{b}$.

Selling to Only One Firm. When a vendor sells to only one firm, the downstream firm will realize $\pi_{a}$ in the pricing subgame (see Figures 3 and 4). It must compare this to the profits that will be realized if it rejects the offer. In the case of two-sided information, a firm that refuses the information will make profit of $\pi_{d}$ in the price competition subgame. This is because the vendor can sell the information to the second firm at a positive price if the first firm refuses it. Accordingly, $\pi_{d}$ represents the equilibrium profits of the firm that does not have the information when the other firm does. Thus, the first firm will pay any price up to $\pi_{a}-$ $\pi_{d}$ for exclusive use of the information.

In the case of one-sided information, the information has different value for the two firms (for one firm it is retention facilitating, and for the other it is conquest facilitating). Thus, when an exclusive offer is rejected, the "rejection" profits can be determined by asking the

\footnotetext{
${ }^{20}$ Under U.S., Canadian, and EC antitrust law, a syndicated data vendor is obliged to sell identical information to downstream firms that compete in the same market for the same consumers at a uniform price. The vendors can charge different prices only if the information packets are different. An indication that price discrimination is not prevalent for the syndicated information discussed in this paper is the fact that ICOM and most other firms publish standardized price lists.
}

following two questions: First, will the second firm be interested (at all) in buying in the information ${ }^{21} \mathrm{Next}$, if the second firm does buy the information, what profits will be nonbuyer of the information realize?

\subsection{One-sided Information}

The following proposition establishes the equilibrium contracting strategy for one-sided information.

Proposition 1. One-sided information will be sold to only one firm.

Suppose the vendor attempts to sell the information to both firms. If both firms have the information, the dominant strategy for the firm for which the modifications are retention type is to implement the modifications regardless of the competitor's strategy. The optimal strategy for the second firm (for which the modifications are conquesting) is to make no modifications. This is because when both firms implement modifications their effects cancel each other. But if the second firm refrains from implementing the conquesting modification, it actually benefits from the competition-reducing positive externality that is created by the retention modification. Thus the second firm has no use for the information and will be unwilling to buy it.

ICOM's approach in the cat food category illustrates this result. In early 1999, the manufacturer of Friskies cat food learned through the ICOM database that loyalty to Friskies was highly correlated with concern for the cat's welfare and interest in activities related to cat ownership. In the spring of 1999, ICOM helped launch the Friskies Cat Club, which provides useful advice on cat ownership, information about cat shows, and special offers. This initiative uses the (one-sided) correlation between loyalty to Friskies and the greater interest in cat ownership activities. ICOM could have also sold its services to manufacturers of competing products such as 9 Lives or Eukanuba. But instead, the vendor has decided on a sole long-term relationship with Nestle (the producer of Friskies) in the canned cat food category. A natural question arising from this example

\footnotetext{
${ }^{21}$ As noted in $\S 3$, there are situations in which conquest-facilitating information is of no value because the modifications in question reduce the profit of the firm implementing them.
} 
is which specific firm in the industry the vendor of onesided information should target. The following proposition considers this question.

Proposition 2. When a vendor possesses one-sided information, his optimal strategy is to sell the information as retention information

(a) when $\beta / t<1.5$, a buyer will not pay a positive price for conquesting information, and

(b) when $\beta / t \geq 1.5$, a buyer will pay a positive price for conquesting information, but this price is strictly lower than the price that can be charged when it is sold as retention information.

Recall that whereas retention modifications always reduce price competition, conquesting modifications of low impact increase price competition. Thus, when one-sided information is of low impact, an attractive price cannot be charged if the information is sold to the firm for whom it is conquesting. Consequently, the vendor sells the information as retention information. In contrast, information that allows "impactful" conquesting modifications can enable a firm to poach on its competitor's customers and to monopolize the market. As a result, a firm will be willing to pay for this information and, thus, sales of conquesting information can potentially generate positive vendor profits. Despite this the vendor continues to make greater profits by selling the information as retention information. This is because even highly impactful conquesting modifications have several disadvantages that limit the selling price a vendor can charge. First, the downstream firms are motivated by the desire to extract surplus from consumers based on the value provided by the modification. This consideration motivates a firm to set a high market price. When conquesting modifications are of particularly high impact, this consideration precludes the focal firm from monopolizing the market because the high price allows the competitor to price such that it can attract some of the consumers who are "near" the focal firm (this is the previously mentioned "backdoor" effect). From the vendor's point of view, this backdoor effect limits her ability to fully extract the market surplus generated by the information. Second, when the loyal consumers of the competition (who are far away on the line) buy from the implementing firm, they incur greater travel costs.
This in turn limits the price that the vendor can charge for conquesting information. As a consequence, even when one-sided information is powerful, the vendor is better off when he sells it as retention information. This is consistent with ICOM's selling policy in the Friskies example; i.e., the vendor chose to sell the information to Friskies and not to the manufacturer of 9 Lives

A further issue is whether the vendor should provide a contractual guarantee of exclusivity to a buyer of retention information. Retention modifications made by a firm have a positive externality on the competitor, and this makes the guarantee of exclusivity worthless for one-sided information (i.e., a firm offered the information as retention type will not pay extra for a guarantee of exclusivity). The reason for this is as follows. If the focal firm uses the one-sided information to implement the retention modification, its competitor does not have an incentive to implement a counteracting conquesting modification even if the information were available for free. Thus, a guarantee of exclusivity is unnecessary for the vendor to credibly sell the information and maintain a high selling price.

This result is interesting as it underlines the selfenforcing nature of the sale of one-sided information to one firm. Even though the value of retention information depends on the competitor not implementing a counteracting conquesting modification, a buyer of retention information need not worry about a guarantee of exclusivity. She knows that her competitor would not implement conquesting modifications even if she had the information to do so.

\subsection{Two-Sided Information}

With two-sided information, the vendor can offer for sale retention packets, conquesting packets, or complete packets containing both retention and conquesting information. The vendor also has an option of selling the complete packet of information exclusively to one firm. (In principle, the vendor might sell restricted packets to only one firm. But, as mentioned before, this is strictly dominated because the highest exclusive price obtains by putting an exclusive buyer in as strong a position as possible.) The equilibrium vendor profits for each option as a function of the modification impact are shown in Table 4.

The following proposition identifies the equilibrium vendor strategies for two-sided information. 
Table 4 Two-Sided Information: Vendor Profit Summary for Different Information "Packaging Strategies"

\begin{tabular}{|c|c|c|c|c|}
\hline \multirow[b]{2}{*}{$\begin{array}{c}\text { Range of } \\
\beta / t\end{array}$} & \multicolumn{3}{|c|}{ Nonexclusive } & \multirow[b]{2}{*}{ Exclusive } \\
\hline & $\begin{array}{c}\text { Retention } \\
\text { Only }\end{array}$ & $\begin{array}{c}\text { Conquesting } \\
\text { Only }\end{array}$ & $\begin{array}{c}\text { Complete } \\
\text { Packets }\end{array}$ & \\
\hline $0,1.5$ & \multirow{6}{*}{$\frac{\beta(7 \beta+15 t)}{9(\beta+2 t)}$} & Not feasible & & \\
\hline $1.5, \sqrt{3}$ & & \multirow[b]{2}{*}{$2 \beta-3 t$} & $\frac{\beta(t \beta+15 t)}{9(\beta+2 t)}$ & $\frac{p}{3}$ \\
\hline$\sqrt{3}, 2$ & & & & \\
\hline 2,3 & & \multirow{3}{*}{$\beta-t$} & $9 t$ & $\frac{r}{3}$ \\
\hline 3,4 & & & $2 \beta-3 t$ & \multirow{2}{*}{$\beta-t$} \\
\hline$>4$ & & & $\beta+t$ & \\
\hline
\end{tabular}

Proposition 3. The equilibrium strategy for a vendor selling two-sided information is as follows:

(a) When the information is of low impact $(\beta / t<\sqrt{3})$, the vendor is indifferent between selling the complete and the retention-only information packets nonexclusively to both the firms.

(b) When $\beta / t \geq \sqrt{3}$, the vendor will sell the complete information packets nonexclusively to both the firms.

The proposition makes two points. First, the strategy of selling to only one firm (even with a contractual guarantee of exclusivity) is not attractive with twosided information. When the information is sold nonexclusively, both firms have the ability to implement retention and conquesting modifications. In this case, we know from Result 2 that the firms will only implement retention modifications in equilibrium. Consequently, both firms enjoy a stronger positive externality and higher profits than when only one firm implements a retention modification. This allows the vendor to charge a selling price that generates more profits than those associated with the price a sole buyer is willing to pay.

There is a second reason for why the nonexclusive strategy is preferred. It is clear that selling to one firm provides a significant advantage to that firm (the buying firm now captures additional market share). However, this advantage is negated by the greater travel costs incurred by consumers who are far away from the firm. This drives down the price the vendor can charge a sole buyer. The vendor is best served by keeping these costs low. A nonexclusive selling strategy ensures that consumers continue to patronize firms that are closer to them and thus creates a downstream situation in which market prices are higher. Ultimately, the vendor benefits from these higher prices by being able to charge a higher selling price.

Discussions with ICOM suggest that in many categories with several major brands the most common type of information is closer to the idea of two-sided information than that of one-sided information. This is because useful correlations are likely to be found with many major brands in a given category. As a result, in spite of being able to charge a premium for exclusive use of its information, a vendor is likely to make greater profits by selling its information to several competitors within a category. ICOM's CEO mentioned that there are instances of firms purchasing exclusivity for a period of time, but the vendor generally discourages it.

The second point pertains to the passive power of information. Recall from Result 2 that firms implement retention modifications only, even when they have the ability to implement both types of modifications. Yet Proposition 3 shows that the equilibrium strategy for the vendor is to sell both firms complete packets of twosided information and not just the information that is ultimately used, i.e., retention information. Clearly, the conquesting information in these complete packets is "passive" in the sense that it is never used. Nevertheless, Proposition 3 demonstrates that this passive information has value. The reason is that the price charged for the information is not simply determined by the equilibrium profits made by the downstream firms. The price is also a function of the (offequilibrium) situation encountered by a firm were it not to buy the information. The inclusion of conquesting information in the packet puts a nonbuyer in a worse situation (if only one firm buys, the buyer will implement both conquesting- and retention-type modifications and put the nonbuyer in a worse situation). This threat allows the vendor to strategically sell the complete packet and extract a higher price from both downstream firms. This highlights the "passive" 
power of information and shows that information can have value even when it is not used.

\section{Managerial Implications and Discussion}

In this section, we examine the relevance of our analysis to observed markets. We discuss how the results are useful for providing guidance to marketing managers about the expected impact of alternative product strategies and to data vendors about the selling of product modification information.

A message of this article is that retention modifications are more likely to be observed in real-world markets. Several authors in the descriptive literature have offered prescriptions that are consistent with this message. For example, Reichheld and Sasser (1990) and Reichheld (1996) have provided evidence from a range of industries that shows that the costs of retaining a firm's loyal customers are much less than the cost of attracting new customers. Our analysis provides a strategic perspective on retention that goes hand-in-hand with the cost-based perspective in the descriptive literature. In the context of product modifications, we have shown that retention modifications have the potential to make one's competitor behave less aggressively and thereby reduce the level of competition in the market. This highlights the importance for practitioners of considering the strategic benefits of modifications that build value for loyal customers (i.e., retention modifications). Furthermore, our analysis suggests that conquesting modifications frequently intensify competition to the detriment of all downstream firms. To proceed with a conquesting modification, a manager must be convinced that the modification is highly impactful and that the competition will be unable to react to the modification. ${ }^{22}$

The model also provides insight about the observed

\footnotetext{
${ }^{22}$ In the case of BreathSavers, research confirmed that the green dot of chlorophyll was a highly impactful modification for the brand. The subsequent market performance of BreathSavers justified this assessment. In 1985, BreathSavers' share had been in decline for more than five years, and its share of the hard rolled candy market was $5.7 \%$ versus Clorets' share of $9.2 \%$. Less than six months after the reformulation, BreathSavers' share increased to over $10 \%$, and Clorets share had declined to under $8 \%$.
}

strategy of many syndicated data vendors. ICOM has a much higher incidence of sales of multiple-brand information than own-brand-only information to downstream clients. Clearly the vendor can subdivide the information and actively promote the sale of restricted information packets (for example, own-brand-only information). However, once the "sunk" cost of collecting the information is incurred, selling complete packets of information to all the firms in the category is typically the strategy that has maximum revenue potential. This is consistent with the message of Proposition 3-that the sale of complete information packets to multiple firms (within a category) allows a vendor to leverage the passive power that results from including conquesting information in the package. A direct managerial prescription that follows from this observation is that the information vendor stands to gain from explicitly publicizing (through standard price lists or through advertising) that complete information packets are available.

\section{Summary and Future Research}

Value-adding modifications to existing products are a common component of the marketing strategy of firms. This strategy is particularly critical in mature categories where firms compete for market share. This article is motivated by the importance of "external" markets for information that allow these modifications. Firms like ICOM, R.L. Polk, Acxiom, and Yankelovich Partners, to name a few, sell syndicated information that is used to facilitate product strategy. This article examines how such information affects the competition between downstream firms and the optimal contracting approach for a vendor who sells it.

The equilibrium contracting strategy for one-sided information is to sell to one firm. As shown in our analysis, it is optimal for a vendor to target her selling effort toward the firm for whom the information facilitates retention modifications. In contrast, two-sided information should always be sold to both firms, as exemplified by ICOM's policy with information in the pain reliever market. Furthermore, the vendor sells the complete packet of information despite the fact that the buyer firms implement only the retention modifica- 
tion. The conquesting information is passive in the sense that it is never used. Nevertheless, the presence of the conquesting information allows the vendor to extract a higher price, because it puts a potential nonbuyer of the information in a worse situation. We call this the passive power of information.

The vendor's selling strategy follows from the effects that retention and conquesting modifications have on downstream competition. Retention modifications have the same effect on competition as increases in product differentiation. Therefore, they unambiguously reduce price competition. In contrast, conquesting modifications can act in a direction opposite to the differentiation between the firms. In general, conquesting modifications either reduce "effective" differentiation in the market or create conditions where firms poach their competitor's loyal customers. Conquesting information can therefore create more intense price competition and a churning of the market. In the information markets studied in this article, the role of conquesting information is most interesting in the context of two-sided information, where its passive power allows a vendor to charge higher prices.

One aspect that we do not explore in this article is the cost of implementing the modifications themselves. We assume that modifications can be made costlessly and that a modified product is produced at the same marginal cost. It would be useful to examine how the vendor's ability to sell the information is affected by implementation costs. An interesting problem is the analysis of modifications other than the value-adding type of modification considered here. For example, firms could modify their products to attract new consumers and thereby expand the market. Another type of modification is one that involves trade-offs; i.e., making the product attractive to some consumers makes it unattractive other consumers. The valueadding modifications discussed here did not have this property. A formal analysis of modifications involving trade-offs should be interesting. Last, the problem of information acquisition is also interesting. If the information vendor first decides whether or not to collect information, an important question is whether she should collect information on specific groups of customers or on the entire market. In sum, investigating markets for information that aids product strategy is a fruitful area for future research. ${ }^{23}$

\section{Appendix}

The appendix for this article can be found on the Marketing Science website at the following URL: 〈http://mktsci.pubs.informs.org $\rangle$.

\section{References}

Admati, Anat R., Paul Pfleiderer. 1986. A monopolistic market for information. J. Econom. Theory 39 400-438.

_ -1988 . Selling and trading on information in financial markets. Amer. Econom. Rev. Papers and Proc. 78 96-103.

-, 1990 . Direct and indirect sale of information. Econometrica 58 (4) $400-438$.

Colombo, Richard A., Donald G. Morrison. 1989. A brand switching model with implications for marketing strategies. Marketing Sci. 8(1) 89-106.

Green, Paul E., Abba M. Krieger. 1989. Recent contributions to optimal product positioning and buyer segmentation. Eur. J. Oper. Res. 41 127-141.

- V. Srinivasan. 1990. Conjoint analysis in consumer research: issues and outlook. J. Marketing 5 (September) 103-123.

Grossman, Sanford J., Joseph E. Stiglitz. 1980. On the impossibility of informationally efficient markets. Amer. Econom. Rev. 70 (3) 393-408.

Hauser, John R., Steven M. Shugan. 1983. Defensive marketing strategies. Marketing Sci. 2(4) 319-360.

Levitt, Theodore. 1969. The Marketing Mode. McGraw-Hill, New York.

Lilien, Gary L., Philip Kotler, K. Sridhar Moorthy. 1992. Marketing Models. Prentice Hall, Engelwood Cliffs, NJ, 245-248.

Moorthy, K. S. 1988. Product and price competition in a duopoly. Marketing Sci. 7 141-168.

Pasa, Mehemet, Steven M. Shugan. 1996. The value of marketing expertise. Management Sci. 42 (3) 370-388.

Preston, Lee E. 1994. Territorial restraints: GTE Sylvania (1977). In The Antitrust Revolution: The Role of Economics. J.E. Kwaka and L.J. White (eds.), HarperCollins Publishers, New York.

Raju, Jagmohan S., Abhik Roy. 1997. Market information and firm performance. Working Paper, The Wharton School, University of Pennsylvania, Philadelphia. PA.

Reicheld, Frederick F. 1996. The Loyalty Effect. Harvard Business School Press, Boston, MA, Ch. 2.

— W. E. Sasser. 1990. Zero defections: quality comes to services. Harvard Bus. Rev. September-October, 105-111.

\footnotetext{
${ }^{23}$ The authors contributed equally to this research and names are listed in alphabetical order. They thank Andy Mitchell, Ambar Rao, Brian Ratchford, the Area Editor, and two anonymous reviewers for their comments. They are also grateful to seminar participants at Duke University, Northwestern University, and the ESSEC/ INSEAD/HEC joint Marketing Seminar (1998), and to Alan Levine and Iris Jacobson of ICOM for their support of this research.
} 


\section{IYER AND SOBERMAN}

Markets for Product Modification Information

Sarvary, Miklos, Philip M. Parker. 1997. Marketing information: A competitive analysis. Marketing Sci. 16 (1) 24-38.

Shaffer, Greg, Florian Zettelmayer. 1999. Bargaining, third-party information and the division of profit in the distribution channel. Working Paper, University of California, Berkeley, CA.

Shaked, A., J. Sutton. 1982. Relaxing price competition through product differentiation. Rev. Econom. Studies 49 3-13.
Smith, Heather. 1998. Putting best practices to work. CIO Canada, January.

Soberman, D. A. 1997. Optimal marketing strategies for static market information. INSEAD Working Paper, 97/25/MKT.

Villas-Boas, Miguel J. 1994. Sleeping with the enemy: should competitors share the same advertising agency? Marketing Sci. 13 190-202.

This paper was received February 3, 1999, and was with the authors 7 months for 2 revisions; processed by Rajiv Lal. 